\title{
Analysis of Composite Membranes in the Separation of Emulsions Sunflower oil/water
}

\author{
Dionisio da Silva Biron ${ }^{a}$, Mara Zeni ${ }^{a}$, Carlos Pérez Bergmann ${ }^{b}$, Venina dos Santos ${ }^{a *}$ \\ ${ }^{a}$ Exact Sciences and Technology Centre - CCET, University of Caxias do Sul - UCS, 95070-560, \\ Caxias do Sul, RS, Brazil \\ ${ }^{b}$ Laboratory of Ceramic Materials, School of Engineering, Federal University of Rio Grande do Sul - \\ UFRGS, Porto Alegre, RS, Brazil
}

Received: September 27, 2016; Revised: February 05, 2017; Accepted: April 09, 2017

\begin{abstract}
Oil is a major pollutant of water resources, affects aquatic life, causing environmental degradation. Currently there is an increase in studies of membrane applied to separation of oil-water. Among these membranes, there are composite membranes, which show as main characteristic an association of organic and inorganic membrane properties. In a tangential flow process, the ceramic tube (support) is responsible for the mechanical strength of the membrane and the selective barrier property of the membrane is established by the polymer. The aim of this work is the application of $\alpha$-alumina/ polyamide 66 composite membrane in the retention of sunflower oil from oil-water emulsions and the study of resistance of such membranes in ultrafiltration processes. The $\alpha$-alumina ceramic tubes were impregnated internally with a solution of polyamide $66(\mathrm{PA} 66)(5 \% \mathrm{w} / \mathrm{v})$ and tested with distilled water and sunflower oil solutions at concentrations of 50, 100 and $200 \mathrm{mg} \cdot \mathrm{L}^{-1}$. Membranes impregnated with PA66 showed a sunflower oil retention between 53.5 and $99.5 \%$ and superior membrane resistance (MR) to the permeate flux $\left(1.92 \times 10^{13}\right.$ a $\left.5.52 \times 10^{13}\right)$ which explains the decrease in the permeate volume.
\end{abstract}

Keywords: Separation, Composite membranes, Ultrafiltration, Sunflower oil

\section{Introduction}

Oil is a water insoluble substance, derived from petroleum, mineral, plant and animal sources. This component has been used in industry, throughout the history, for example, as a lubricant in metalworking, becoming indispensable in industry processes $^{1,2}$. As a result of these processes, a significant amount of oil has been generated in the form of emulsions of oil in water or water in oil for petrochemical industries, transport and metal-mechanics industries ${ }^{3}$.

Currently studies have sought alternatives to replace oil derived from non-renewable sources, the use of vegetable oils in an important one. These materials can not only substitute mineral oil, but also provide a renewable character ${ }^{2-4}$.

Oil is a major pollutant of water resources, affects aquatic life, causing environmental degradation. Generally, a stable oil-water emulsion shows oil droplets of a size up to $20 \mu \mathrm{m}$. Even with the presence of oil-water interface, the oil phase cannot be separated by simple gravity, a most appropriate treatment process is required ${ }^{4-5}$.

Several technologies have been developed in the demulsification of oil-water solutions. The centrifugal separation, chemical sedimentation, flotation and membrane separation processes are used for oil removal. To increase the quality of these processes, the study of membranes for the retention of oil plays an important role. Transmembrane pressure is a driving force for this technology, which

*e-mail: vsantos2@ucs.br forces the passage of emulsified liquid by a porous system (membrane), performing the retention of oil on the surface of the material ${ }^{6-7}$. Membrane technology has advantages as lower space required, low cost and possibility to separate streams with low concentrations, reaching high efficiencies (90-99\%). Typically, the oil concentration in the feed varies from 50 to $1000 \mathrm{mg} \cdot \mathrm{L}^{-1}$, and the final concentration after the process of $10-15 \mathrm{mg} \cdot \mathrm{L}^{-1}$ is desired ${ }^{8-12}$.

The use of membranes provides numerous advantages, however a difficulty to the continuity of the permeate flux is observed in membrane processes, as in any other real physical process where there are moving between distinct parties. The main constraints to the permeate flux are: concentration polarization, polarized layer and fouling. For a process using membranes, to know and to control these characteristics are essential for the viability of the process. However, physical processes such as mechanical removal or backwashing, and chemical methods such as the use of acidic or alkaline solutions are needed to recover the permeate flux, partially or totally ${ }^{13-15}$.

Several studies have demonstrated the effectiveness of using ultrafiltration membranes with tangential flux in oil separation processes, which provide satisfactory results. Membranes for demulsification are compact modules and can work continuously ${ }^{16-18}$. The aim of this study is to obtain a composite filter system with greater selectivity, composed of an inorganic and organic material ( $\alpha$-alumina/PA66). The polymeric layer is responsible for the selectivity, and the ceramic 
support allowed the necessary support to the polymer film ${ }^{19}$, and also to emphasize the study of membrane resistance by the retention of sunflower oil of the oil-water solutions. In the experiments of oil-water were used oil concentrations of 50,100 and $200 \mathrm{mg} \cdot \mathrm{L}^{-1}$, and transmembrane pressures of $150,200,250$ and $300 \mathrm{kPa}$.

It is important to highlight that the composite membranes with a layer of polyamide 66 (PA-1) and with two layers of polyamide 66 (PA-2) and the ceramic support were characterized in previous study ${ }^{20}$.

\section{Experimental}

\subsection{Preparation of the composite membrane}

The membrane was prepared by dip-coating from polyamide 66 solution (PA66) (RhodiaTechnyl) inside the tubular ceramic support (pore diameter of $0.65 \mu \mathrm{m}$ ) (Tecnicer-Celebra, São Carlos - Brazil). The PA66 solution was prepared at a concentration of $5 \%(\mathrm{w} / \mathrm{v})$ using formic acid $(\mathrm{HCOOH})($ Vetec) as solvent. The deposition of the polymeric solution was carried in the inner part the ceramic tube. The ceramic tube was closed on one side and the solution kept in the tube for two hours. Excess solution was removed, and the tube immersed in distilled water for 30 min in order to form the selective layer of PA66 by reverse phase process ${ }^{20}$. The composite membrane remained for 6 $\mathrm{h}$ at $30^{\circ} \mathrm{C}$ in a vacuum oven to remove the excess solvent. The process was repeated to perform the deposition of the second layer of PA66.

\subsection{Tangential ultrafiltration system}

The separations of oil-water emulsions were made into a bench ultrafiltration system, as shown in Figure 1. All microfiltration tests in this work were performed at a feed temperature of $20 \pm 2^{\circ} \mathrm{C}$. The system comprises a feed tank of $3 \mathrm{~L}$, pumping system with a diaphragm pump with 3 chambers from Positive Displacement and motor from Permanent Magnet P/N 11-155-05. The working flux used was 0.93 L. $\mathrm{min}^{-1}$ with theoretical Reynolds number, calculated, of 2,630.

\subsection{Membrane characterization with distilled water}

The commercial ceramic support and the composite membrane were characterized by distilled water flux at pressures of 150,200, 250 and $300 \mathrm{kPa}$ and calculated according to Eq. (1). Each experiment was performed by $120 \mathrm{~min}$ and pressure changes occurred during this process, i.e. a different pressure was used for $30 \mathrm{~min}$ over the course of the experiment. The purpose of this procedure was to

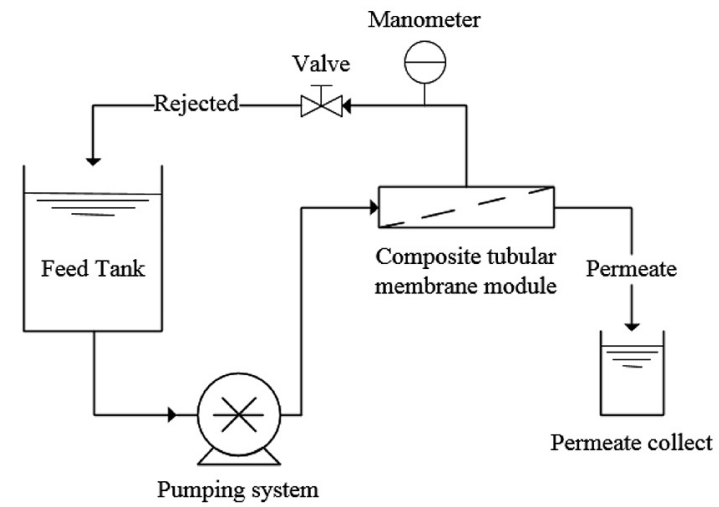

Figure 1. System used in the process of microfiltration.

determine the maximum transmembrane flux (membrane performance), and to calculate the resistance before any modification in the porous layer, as an obstruction of the membrane pores by oil droplets, for instance.

$$
\mathrm{J}_{\mathrm{w}}=\frac{\mathrm{V}}{\mathrm{A} \cdot \Delta \mathrm{t}}
$$

Where $\mathrm{J}_{\mathrm{w}}$ is the permeate flux to distilled water $\left(\mathrm{L} \cdot \mathrm{m}^{-2} \cdot \mathrm{h}^{-1}\right)$, $\mathrm{V}$ is the volume of permeate (L), A is the useful membrane area $\left(\mathrm{m}^{2}\right)$ and $\Delta \mathrm{t}$ is the permeation time $(\mathrm{h})$

\subsection{Permeate flux of oil and water and determination of oil rejection}

The permeate flow of oil and water was obtained at pressures of $150,200,250$ and $300 \mathrm{kPa}$. The oil concentrations of the solutions were 50,100 and $200 \mathrm{mg} \cdot \mathrm{L}^{-1}$. For the preparation of the oil/water emulsions was used distilled water and commercial sunflower oil. The emulsion was prepared by mechanically stirring for 10 minutes to $10,000 \mathrm{rpm}^{22}$. The mechanical stirring resulted an oil droplet size of approximately $12.1 \pm 5 \mu \mathrm{m}$. Eq. (1) was used to calculate the permeate flux. Oil retention was measured using a spectrophotometer (GENESYS 10 UV Ultraviolet Spectrophotometer, Thermo Spectronic UV-visible) wavelength in $210 \mathrm{~nm}$. Eq. (2) was used to calculate rejection:

$$
\% \mathrm{OR}=\left(1-\frac{\mathrm{Cp}}{\mathrm{Cf}}\right)
$$

Where $\% \mathrm{OR}$ is the oil retention, $\mathrm{Cp}$ is the permeate oil concentration and $\mathrm{Cf}$ is the feed oil concentration.

\subsection{Membrane Resistance (MR)}

The membrane resistance is due to geometrical factors such as size, pore distribution, thickness and the affinity of the membrane surface with solvent. 
Permeate flux, with distilled water, was used to calculate the resistance of the membrane in a free change membrane, the value was obtained from Eq. (3).

$$
\mathrm{MR}=\frac{\Delta \mathrm{P}}{\mathrm{n}_{\mathrm{w}} . J_{\mathrm{w}}}
$$

Where $\Delta \mathrm{P}$ is the variation in pressure $(\mathrm{kPa}), \mathrm{n}_{\mathrm{w}}$ is the dynamic viscosity of the liquid and MR is the resistance of the membrane.

\subsection{Fouling Resistance (FR)}

The fouling resistance is obtained after ultrafiltration process when distilled water pass through a membrane, it means, when permeate flux loss occurs due to oil droplets which were adhered to the membrane surface. Eq. (4) was used to determine the fouling resistance.

$$
\mathrm{FR}=\frac{\Delta \mathrm{P}}{\mathrm{n}_{\mathrm{w}} \cdot \mathrm{J}_{\mathrm{w}}}-\mathrm{MR}
$$

Where $n_{w}$ regards the properties of the oil-water solution and FR is the fouling resistance.

\subsection{Resistance to polarization (RP)}

The concentration polarization occurs when the solids are entrained to the membrane surface by convective transport and partially or totally rejected, the solids tend to concentrate on the interface, forming a concentration gradient. Eq. (5) was used to calculate the polarization resistance.

$$
\mathrm{RP}=\mathrm{TR}-\mathrm{MR}-\mathrm{FR}
$$

Where RP is the polarization resistance and TR is the total resistance of the membrane, i.e. the resistance that occurs during the ultrafiltration.

Eq. (1) was used to determine total membrane resistance, where the properties of the liquid employed were the oilwater solution.

\section{Results and Discussion}

\subsection{Pure water Flux}

Figure 2 shows the results of permeate flux for ceramic tube (support) and for membrane with one and two layers of polyamide 66 (PA-1 and PA-2, respectively).

Support showed higher permeate flux in all filtrations, but decreased significantly throughout the tests in relation to PA-1 and PA-2. Initially support flux was $300 \mathrm{~L} \cdot \mathrm{m}^{-2} \cdot \mathrm{h}^{-1}$ at a pressure of $300 \mathrm{kPa}$, the permeate flux in the last test showed a recovery from 42 to $73 \mathrm{~L} \cdot \mathrm{m}^{-2} \cdot \mathrm{h}^{-1}$. The permeate water flux, in a pressure of $150 \mathrm{kPa}$, was around $31 \mathrm{~L} \cdot \mathrm{m}^{-2} \cdot \mathrm{h}^{-1}$.

PA-1 and PA-2 filtration tests showed lower permeate flux than support, however, they showed a smaller drop in the beginning of the process than support. One can see a close agreement between the permeate flux of PA-1 and PA-2, especially in the pure water test, Figure 2 (a), demonstrating a possible inefficiency in impregnation of the first polymer layer or even the second layer, since they showed similar results.

The decrease in permeate flux presented by the ceramic tube and the membrane is due to the increased concentration of oil in the emulsion, forming a cake layer, which rapidly blocks the passage of the permeate flux ${ }^{17-23}$. The membrane was cleaned with a solution containing distilled water and neutral detergent. The neutral detergent concentration was $2 \%(\mathrm{v} / \mathrm{v})$.

\subsection{Oil-water flux and oil rejection}

Figure 3 shows the results of oil-water permeate flux for the membranes.

A more significant decrease in the permeate flux of support in relation to PA-1 and PA-2 can be observed. This shows a more significant increase of oil on the surface of the ceramic support, causing the reduction on permeate flux ${ }^{13,15,17}$.

The oil retention of membranes is shown in Figure 4. The support showed lower values than PA-1 and PA-2, around 43.3 and $92.3 \%$. The PA-1 showed values around 53.8 and $97.7 \%$, while PA-2 showed values around $96 \%$, reaching an efficiency of $99.5 \%$. The minimum and maximum values, presented previously, obtained from the composite membranes and the ceramic support, can be verified in sunflower oil concentration of $50 \mathrm{mg} \cdot \mathrm{L}^{-1}$ with applied pressure of 300 $\mathrm{kPa}$ and in sunflower oil concentration of $200 \mathrm{mg} \cdot \mathrm{L}^{-1}$ with applied pressure of $150 \mathrm{kPa}$, respectively.

Table 1 shows the comparative result of the permeate flux obtained by the ceramic support and the PA-1 and PA-2 membranes. When we analyze the Table 1, we observe that in concentration of $50 \mathrm{mg} \cdot \mathrm{L}^{-1}$ of sunflower oil with transmembrane pressure of $300 \mathrm{kPa}$ the average permeate flux was $137.6 \mathrm{~L} \cdot \mathrm{m}^{-2} \cdot \mathrm{h}^{-1}$ for the ceramic support and 32.5 $\mathrm{L} \cdot \mathrm{m}^{-2} \cdot \mathrm{h}^{-1}$ for the PA-1 membrane, which corresponds to $76.4 \%$ more of permeate flux for the ceramic support. Under the same conditions, we verified that the ceramic support presents $86.9 \%$ more of permeate flux in relation to PA-2 membrane. That difference in permeate flux between PA-1 and PA-2 is due to larger coating of the pores of ceramic support by the polymeric layer, and it occurred more in the membrane with two layers of PA $66^{20}$. In the operation conditions of $200 \mathrm{mg} \cdot \mathrm{L}^{-1}$ of sunflower oil concentration and transmembrane pressure of $150 \mathrm{kPa}$ we see a reduction of this difference. The average permeate flux for the ceramic support, in the conditions presented, in relation to PA-1 and PA-2 membranes, was around $24.8 \%$ and $56.4 \%$ more, respectively. That approximation may be related to the hydrophilic character presented by PA66, which repels the oil droplets. 

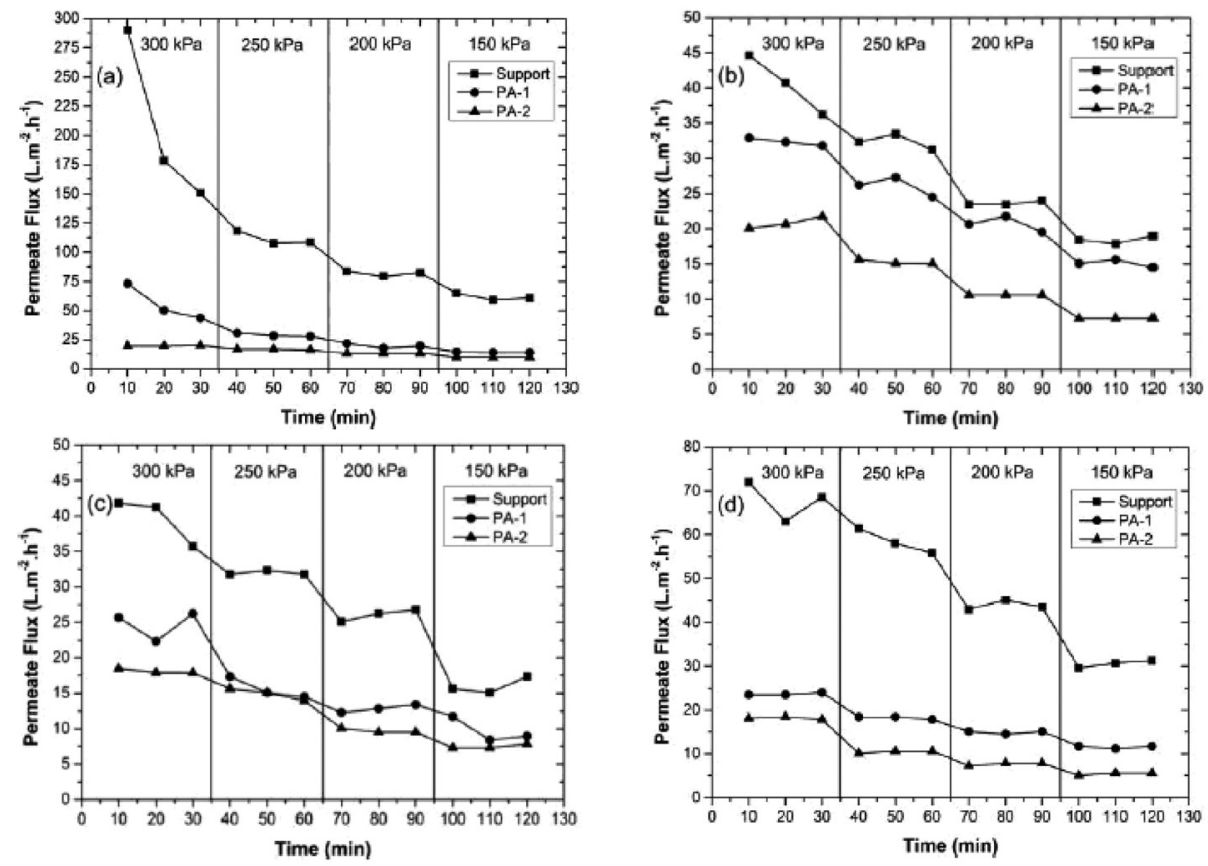

Figure 2. Water flux tests (a) starting with pure water, (b) after the ultrafiltration with oil concentration of 50 $\mathrm{mg} \cdot \mathrm{L}^{-1}$, (c) after ultrafiltration test with oil concentration of $100 \mathrm{mg} \cdot \mathrm{L}^{-1}$ and (d) after the ultrafiltration with oil concentration of $200 \mathrm{mg} \cdot \mathrm{L}^{-1}$.
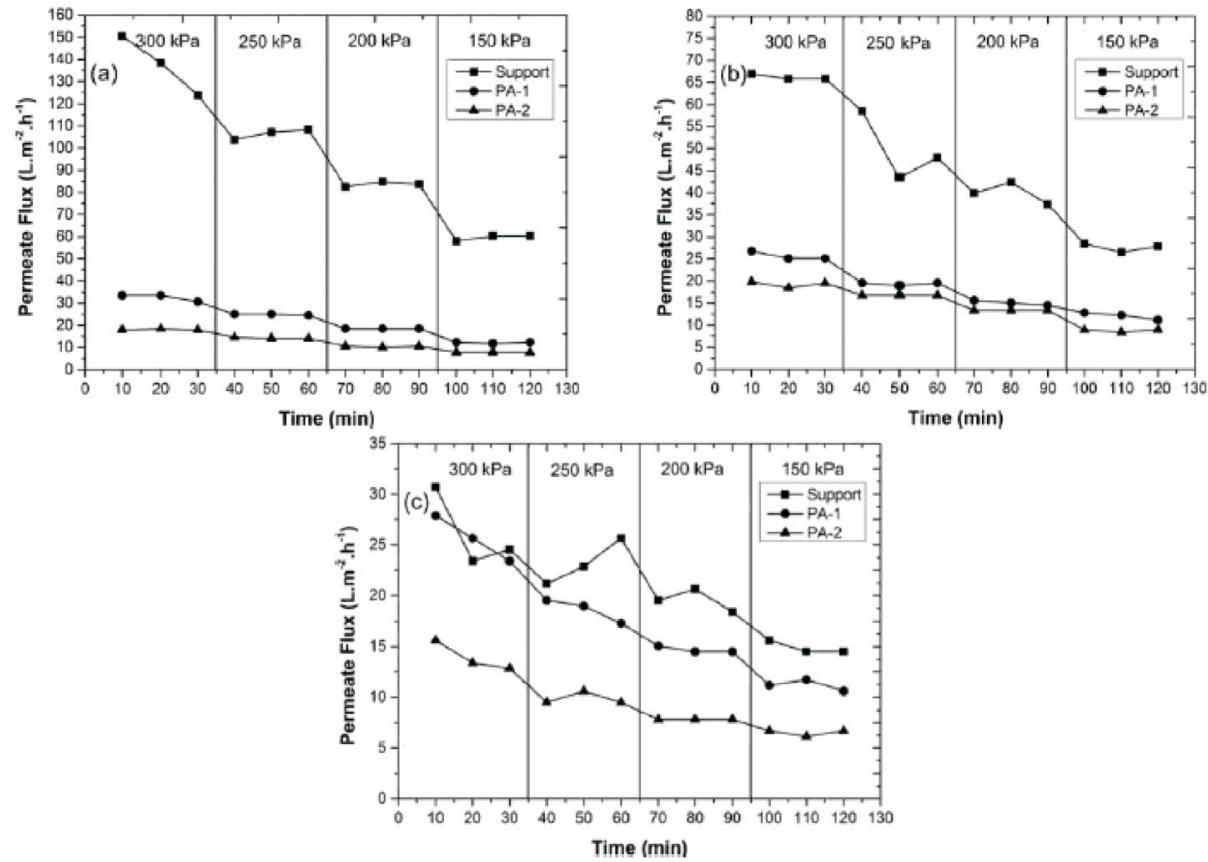

Figure 3. Oil-water flux for oil concentrations of (a) $50 \mathrm{mg} \cdot \mathrm{L}^{-1}$, (b) $100 \mathrm{mg} \cdot \mathrm{L}^{-1}$ and (c) $200 \mathrm{mg} \cdot \mathrm{L}^{-1}$.

When we compared the PA-1 and PA-2 membranes, we observed that, at the concentration of $50 \mathrm{mg} \cdot \mathrm{L}^{-1}$ of sunflower oil and $300 \mathrm{kPa}$ applied pressure, the flux was $44.6 \%$ more for the PA-1 membrane. The same occurs in the concentration of
$200 \mathrm{mg} \cdot \mathrm{L}^{-1}$ of sunflower oil and transmembrane pressure of $150 \mathrm{kPa}$, in others words, the average permeate flux remained around $41.9 \%$ more for PA-1 membrane. The PA- 2 membrane presents a smaller permeate flux due to the greater recoating of the pores of the ceramic support by PA66. 

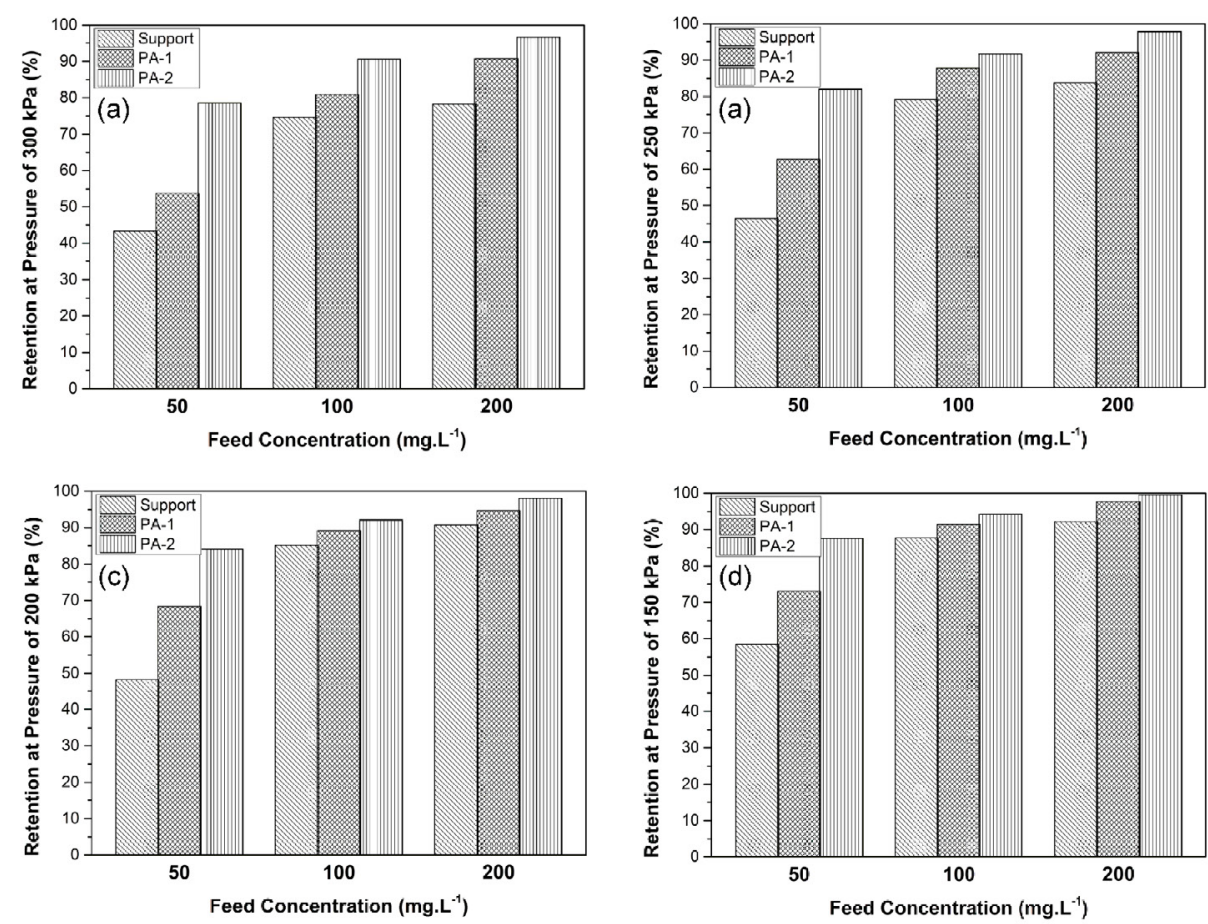

Figure 4. Results for oil rejection in the following pressures (a) $300 \mathrm{kPa}$, (b) $250 \mathrm{kPa}$, (c) $200 \mathrm{kPa}$ and (d) $150 \mathrm{kPa}$.

The significantly better oil retention in PA-1 and PA- 2 is due to the use of polymeric skin in order to provide superior oil separation, increasing retention, but also showed a significant decrease in permeate flux (Figure 2) ${ }^{24}$. The retention capacity of the composite membranes can be understood due to two mechanisms: 1) the skin formed on the surface of the porous material has lower porosity and prevents the passage of the oil droplets and 2) the deposited polymeric skin has hydrophilic properties and this skin shows aversion to oil.

\subsection{Membrane Resistance (MR)}

Membrane resistance values at different pressure are shown in Figure 5. PA-2 showed greater resistance to the passage of water, due the thickness of the polymer layer impregnated on the support. Support showed the lowest resistance, due to the fact that the support does not present any additional resistance to permeate flow, because there is not the polymeric layer, which increases the resistance of the membrane.

PA-2 membrane showed an increase in resistance with the increase in pressure, but on the other hand, the PA-1 and support membranes showed a decrease in resistance with the increase in pressure. Increase in membrane resistance is imminent from two layers of polymer, it also explains the lower flux of the PA- $2^{17}$. The increase of the membrane

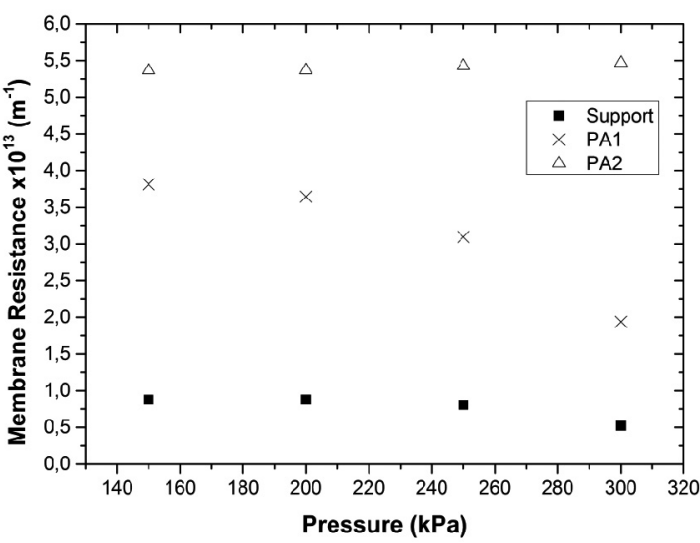

Figure 5. Membranes resistance analysis by pressure.

resistance for PA-2 occurs due to a greater surface coating of the pores of the ceramic support, as can be seen in the SEM, Figure 4 (e), obtained in the previous paper ${ }^{20}$.

\subsection{Fouling Resistance (FR)}

Figure 6 shows the variation of the fouling resistance by pressure. The resistance support is shown above PA-1 and PA-2 in the test, however, over the course of the tests a significant increase in its resistance had exceeded PA-1. In tests, PA-1 showed an increase in its FR during the ultrafiltration, while support and PA-2 decreased, Figure 6 (b). 
Table 1. Result of average values of the permeate flux to the ceramic support and to the PA-1 and PA-2 membranes.

\begin{tabular}{|c|c|c|c|}
\hline Membranes & Oil concentration $\left(\mathrm{mg} \cdot \mathrm{L}^{-1}\right)$ & Pressure $(\mathrm{kPa})$ & Average permeate flux $\left(\mathrm{L} \cdot \mathrm{m}^{-2} \cdot \mathrm{h}^{-1}\right)$ \\
\hline \multirow{12}{*}{ Support } & \multirow{4}{*}{50} & 300 & 137.6 \\
\hline & & 250 & 106.3 \\
\hline & & 200 & 83.7 \\
\hline & & 150 & 59.5 \\
\hline & \multirow{4}{*}{100} & 300 & 66.2 \\
\hline & & 250 & 50 \\
\hline & & 200 & 39.9 \\
\hline & & 150 & 27.6 \\
\hline & \multirow{4}{*}{200} & 300 & 26.2 \\
\hline & & 250 & 23.2 \\
\hline & & 200 & 19.5 \\
\hline & & 150 & 14.9 \\
\hline \multirow{12}{*}{ PA-1 } & \multirow{4}{*}{50} & 300 & 32.5 \\
\hline & & 250 & 24.9 \\
\hline & & 200 & 18.4 \\
\hline & & 150 & 12.1 \\
\hline & \multirow{4}{*}{100} & 300 & 25.7 \\
\hline & & 250 & 19.3 \\
\hline & & 200 & 15 \\
\hline & & 150 & 12.1 \\
\hline & \multirow{4}{*}{200} & 300 & 25.6 \\
\hline & & 250 & 18.6 \\
\hline & & 200 & 14.7 \\
\hline & & 150 & 11.2 \\
\hline \multirow{12}{*}{ PA-2 } & \multirow{4}{*}{50} & 300 & 18 \\
\hline & & 250 & 14.1 \\
\hline & & 200 & 10.4 \\
\hline & & 150 & 7.8 \\
\hline & \multirow{4}{*}{100} & 300 & 19.2 \\
\hline & & 250 & 16.7 \\
\hline & & 200 & 13.4 \\
\hline & & 150 & 8.7 \\
\hline & \multirow{4}{*}{200} & 300 & 13.9 \\
\hline & & 250 & 9.9 \\
\hline & & 200 & 7.8 \\
\hline & & 150 & 6.5 \\
\hline
\end{tabular}

The fouling resistance of PA- 1 was increased by the applied pressure, Figure 6, because for greater pressures there is a stronger compression of solute on the surface causing increased flow obstruction ${ }^{25,26}$. Moreover, the increased pressure in the test with PA-2 resistance decreases, showing that the application of pressure ruptures the resistance exerted by fouling.

\subsection{Total Resistance (TR)}

Total resistance values for the membranes are shown in Figure 7 as a function of transmembrane pressure. It was not observed significant difference between the applied pressures, however, the increase of the polyamide layers influenced in the increase of the total membrane resistance, which justifies the lower permeate flux obtained by the composite membranes in the microfiltration processes ${ }^{24}$. 

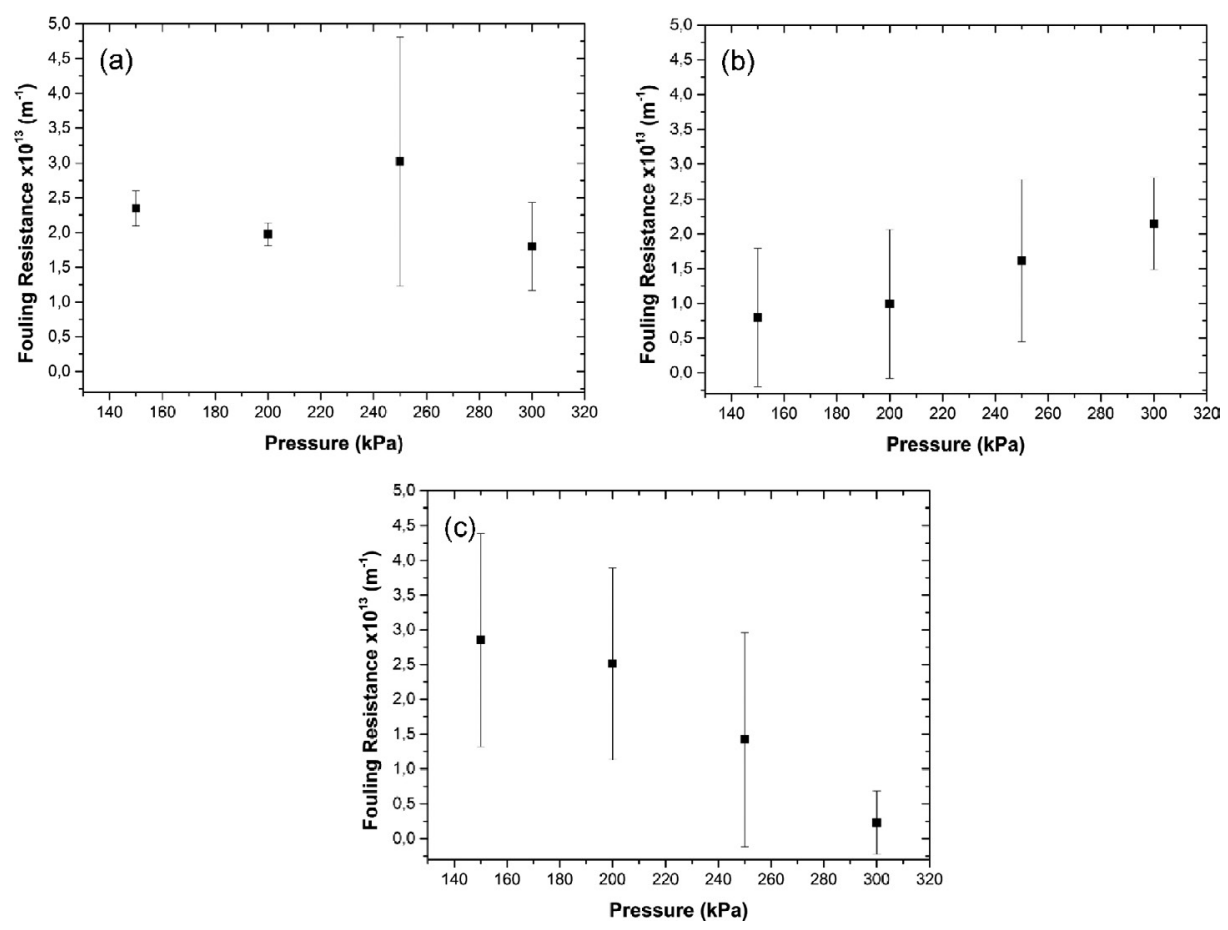

Figure 6. Analysis of fouling resistance of membranes by pressure. (a) Support, (b) PA-1 and (c) PA-2.
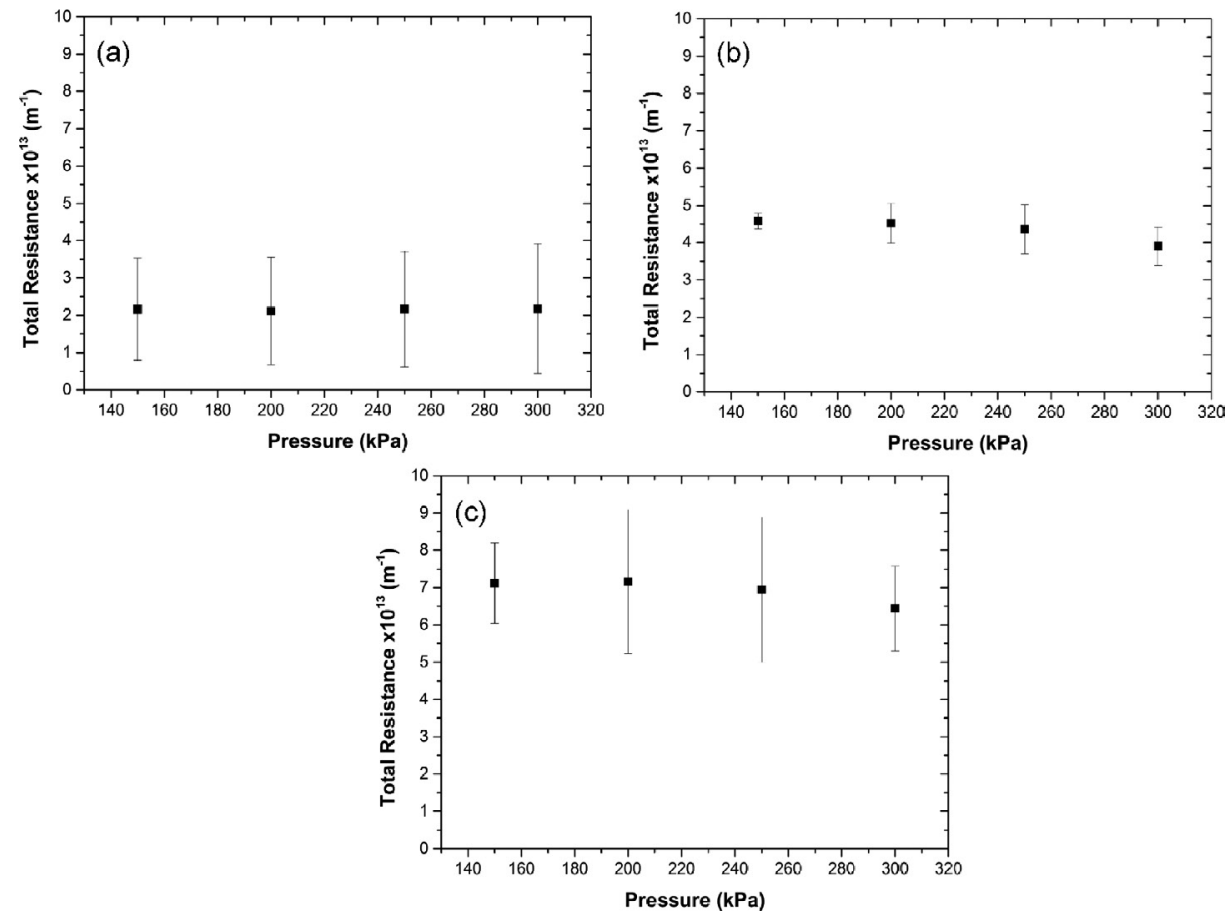

Figure 7. Analysis of the total resistance of membranes by pressure. (a) Support, (b) PA-1 and (c) PA-2.

\subsection{Resistance to polarization $(R P)$}

The polarization resistance according to the transmembrane pressure can be seen in Figure 8. A decrease in resistance in PA-2 for both tests can be observed, the increased pressure neither created a polarized layer nor increased the polarization layer. Differently, support and PA-1 have maintained their resistance throughout the tests ${ }^{27}$.

The calculation of the polarization resistance for the membranes resulted in negative values. Possibly, negative values are due fluctuation in the viscosity determination of the permeated and the water, resulting in total resistance smaller than the sum of 

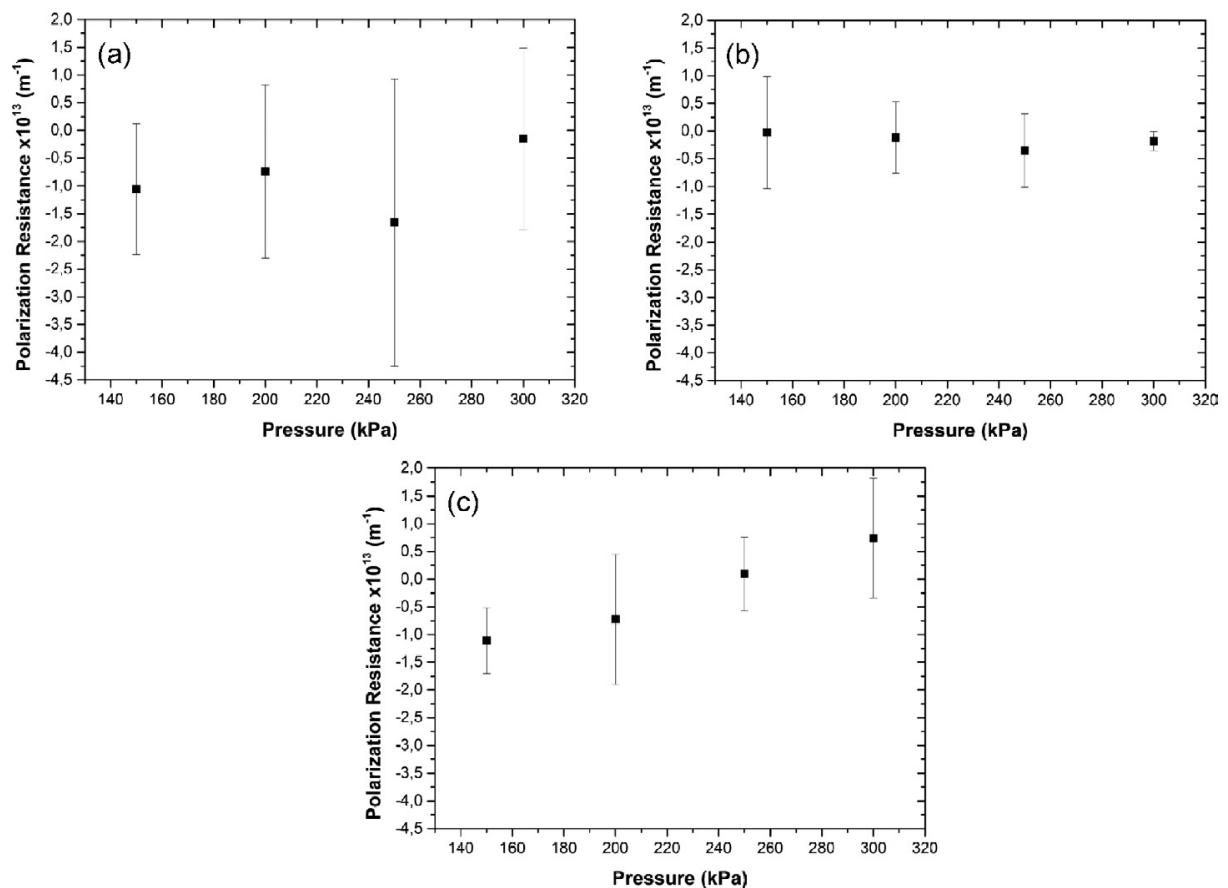

Figure 8. Analysis of the polarization resistance of membranes by pressure. (a) Support, (b) PA-1 and (c) PA-2.

Table 2. Percentage contribution of each type of obstruction with oil concentration of $50 \mathrm{mg} \cdot \mathrm{L}^{-1}$.

\begin{tabular}{|c|c|c|c|c|c|}
\hline Membrane & Pressure $(\mathrm{kDa})$ & $\operatorname{TR}\left(\mathrm{m}^{-1}\right) \times 10^{13}$ & $\mathrm{MR}(\%)$ & FR(\%) & $\mathrm{RP}(\%)$ \\
\hline \multirow{4}{*}{ Support } & 300 & 0.78 & $67 \%$ & $33 \%$ & $0 \%$ \\
\hline & 250 & 0.84 & $95 \%$ & $5 \%$ & $0 \%$ \\
\hline & 200 & 0.86 & $100 \%$ & $0 \%$ & $0 \%$ \\
\hline & 150 & 0.91 & $97 \%$ & $3 \%$ & $0 \%$ \\
\hline \multirow{4}{*}{ PA-1 } & 300 & 3.31 & $59 \%$ & $41 \%$ & $0 \%$ \\
\hline & 250 & 3.60 & $86 \%$ & $10 \%$ & $4 \%$ \\
\hline & 200 & 3.90 & $93 \%$ & $0 \%$ & $7 \%$ \\
\hline & 150 & 4.46 & $86 \%$ & $0 \%$ & $14 \%$ \\
\hline \multirow{4}{*}{ PA-2 } & 300 & 5.98 & $92 \%$ & $0 \%$ & $8 \%$ \\
\hline & 250 & 6.36 & $85 \%$ & $7 \%$ & $7 \%$ \\
\hline & 200 & 6.90 & $78 \%$ & $20 \%$ & $2 \%$ \\
\hline & 150 & 6.90 & $78 \%$ & $22 \%$ & $0 \%$ \\
\hline
\end{tabular}

Table 3. Percentage contribution of each type of obstruction with oil concentration of $100 \mathrm{mg} \cdot \mathrm{L}^{-1}$.

\begin{tabular}{|c|c|c|c|c|c|}
\hline Membrane & Pressure (kDa) & $\mathrm{TR}\left(\mathrm{m}^{-1}\right) \times 10^{13}$ & $\mathrm{MR}(\%)$ & $\mathrm{FR}(\%)$ & $\mathrm{RP}(\%)$ \\
\hline \multirow{4}{*}{ Support } & 300 & 4.11 & $13 \%$ & $53 \%$ & $34 \%$ \\
\hline & 250 & 3.86 & $21 \%$ & $52 \%$ & $27 \%$ \\
\hline & 200 & 3.68 & $24 \%$ & $51 \%$ & $25 \%$ \\
\hline & 150 & 3.62 & $24 \%$ & $69 \%$ & $7 \%$ \\
\hline \multirow{4}{*}{ PA-1 } & 300 & 4.20 & $46 \%$ & $54 \%$ & $0 \%$ \\
\hline & 250 & 4.64 & $55 \%$ & $45 \%$ & $0 \%$ \\
\hline & 200 & 4.77 & $66 \%$ & $34 \%$ & $0 \%$ \\
\hline & 150 & 4.46 & $74 \%$ & $26 \%$ & $0 \%$ \\
\hline \multirow{4}{*}{ PA-2 } & 300 & 5.60 & $91 \%$ & $9 \%$ & $0 \%$ \\
\hline & 250 & 5.37 & $94 \%$ & $6 \%$ & $0 \%$ \\
\hline & 200 & 5.37 & $81 \%$ & $19 \%$ & $0 \%$ \\
\hline & 150 & 6.17 & $77 \%$ & $23 \%$ & $0 \%$ \\
\hline
\end{tabular}


Table 4. Percentage contribution of each type of obstruction with oil concentration of $200 \mathrm{mg} \cdot \mathrm{L}^{-1}$.

\begin{tabular}{|c|c|c|c|c|c|}
\hline Membrane & Pressure $(\mathrm{kDa})$ & $\operatorname{TR}\left(\mathrm{m}^{-1}\right) \times 10^{13}$ & $\operatorname{MR}(\%)$ & $\operatorname{FR}(\%)$ & $\mathrm{RP}(\%)$ \\
\hline \multirow{4}{*}{ Support } & 300 & 1.63 & $32 \%$ & $65 \%$ & $2 \%$ \\
\hline & 250 & 1.80 & $0 \%$ & $100 \%$ & $0 \%$ \\
\hline & 200 & 1.80 & $23 \%$ & $77 \%$ & $0 \%$ \\
\hline & 150 & 1.95 & $9 \%$ & $91 \%$ & $0 \%$ \\
\hline \multirow{4}{*}{ PA-1 } & 300 & 4.20 & $42 \%$ & $58 \%$ & $0 \%$ \\
\hline & 250 & 4.83 & $63 \%$ & $37 \%$ & $0 \%$ \\
\hline & 200 & 4.89 & $75 \%$ & $24 \%$ & $1 \%$ \\
\hline & 150 & 4.83 & $79 \%$ & $18 \%$ & $3 \%$ \\
\hline \multirow{4}{*}{ PA-2 } & 300 & 7.73 & $71 \%$ & $6 \%$ & $23 \%$ \\
\hline & 250 & 9.11 & $60 \%$ & $35 \%$ & $5 \%$ \\
\hline & 200 & 9.20 & $57 \%$ & $43 \%$ & $0 \%$ \\
\hline & 150 & 8.28 & $54 \%$ & $46 \%$ & $0 \%$ \\
\hline
\end{tabular}

$\mathrm{R}_{\mathrm{M}}$ and $\mathrm{R}_{\mathrm{F}}$. However, these data may be analyzed as near zero, indicating that there was virtually no resistance to flow caused by concentration by polarization and the polarized layer ${ }^{27}$.

\subsection{Resistance contribution}

Tables 2, 3 and 4 show the percentage contribution caused by the permeate flux for each type of obstruction, membrane, fouling and polarization, for oil concentration of 50,100 and $200 \mathrm{mg} \cdot \mathrm{L}^{-1}$. The fouling membrane was 65 at $100 \%$ for the test performed at $200 \mathrm{mg} \cdot \mathrm{L}^{-1}$ for support, due the diameter of the oil droplets, which penetrate the pores causing fouling ${ }^{15}$. In experiments the contribution of membrane resistance varies in a wide range of 0 to $100 \%$ and fouling resistance from 0 to $100 \%$ and polarization resistance from 0 to $34 \%$.

The fouling resistance is most significant in support, justifying for its permeate flux reduction during the tests ${ }^{26}$.

The polarized layer and concentration by polarization proved several time contributions of $0 \%$, with a variation from 0 to $27 \%$, for membranes studied. The largest contribution is the membrane resistance and fouling resistance, explaining the decrease of flux in the initial phase of the tests ${ }^{17}$.

\section{Conclusion}

The use of composite membrane is effective in removing oil from oil-water solutions in the concentrations tested, according to the results. However, the permeate flux had a significant decreasing because of the presence of PA66 layer on the inner surface of the support. Ceramic support retained the oil in a range of 43.3 to $92.3 \%$, while the membranes of one and two layers of polyamide 66 showed an oil rejection of 53.8 to $97.7 \%$, and $78.5 \%$ to $99.5 \%$, respectively.

The membrane resistance showed a significant contribution on total resistance, ranging between 0 and $100 \%$, followed by fouling resistance ranging between 0 and $100 \%$ and the polarized layer and concentration polarization ( 0 to $34 \%$ ). Therefore, the application of these membranes under the operational point of view proves to be feasible, since the process ensures higher quality of the final effluent. However, a larger area is necessary due to reduction in transmembrane flux when a selective layer of polyamide 66 is employed.

\section{Acknowledgments}

The authors would like to acknowledge the CNPq, CAPES for financial support.

\section{References}

1. John J, Bhattacharya M, Raynor PC. Emulsions containing vegetable oils for cutting fluid application. Colloids and Surfaces A: Physicochemical and Engineering Aspects. 2004;237(1-3):141150. DOI: $10.1016 /$ j.colsurfa.2003.12.029

2. Graboski MS, McCormick RL. Combustion of fat and vegetable oil derived fuels in diesel engines. Progress in Energy and Combustion Science. 1998;24(2):125-164. DOI: 10.1016/ S0360-1285(97)00034-8

3. Chen W, Peng J, Su Y, Zheng L, Wang L, Jiang Z. Separation of oil/water emulsion using Pluronic F127 modified polyethersulfone ultrafiltration membranes. Separation and Purification Technology. 2009;66(3):591-597. DOI: 10.1016/j.seppur.2009.01.009

4. Abadi SRH, Sebzari MR, Hemati M, Rekabdar F, Mohammadi T. Ceramic membrane performance in microfiltration of oily wastewater. Desalination. 2011;265(1-3):222-228. DOI: 10.1016/j.desal.2010.07.055

5. Chang Q, Zhou J, Wang Y, Liang J, Zhang X, Cerneaux S, et al. Application of ceramic microfiltration membrane modified by nano $\mathrm{TiO}_{2}$ coating in separation of a stable oil-in-water emulsion. Journal of Membrane Science. 2014;456:128-133. DOI: 10.1016/j.memsci.2014.01.029

6. Rao DG, Senthikumar R, Byrne JA, Feroz S. Wastewater Treatment: Advanced Processes and Technologies. London: IWA Publishing; 2012. 388 p. 
7. van der Sman RGM, Vollebregt HM, Mepschen A, Noordman TR. Review of hypotheses for fouling during beer clarification using membranes. Journal of Membrane Science. 2012;396:22-31. DOI: $10.1016 /$ j.memsci.2011.12.051

8. Ebrahimi M, Willershausen D, Ashaghi KS, Engel L, Placido $\mathrm{L}$, Mund $\mathrm{P}$, et al. Investigations on the use of different ceramic membranes for efficient oil-field produced water treatment. Desalination. 2010;250(3):991-996. DOI: 10.1016/j. desal.2009.09.088

9. Emani S, Uppalurin R, Purkaitnn MK. Microfiltration of oil-water emulsions using low cost ceramic membranes prepared with the uniaxial dry compaction method. Ceramics International. 2014;40(1 PtA):1155-1164. DOI: 10.1016/j.ceramint.2013.06.117

10. Kukizaki M, Goto M. Demulsification of water-in-oil emulsions by permeation through Shirasu-porous-glass (SPG) membranes. Journal of Membrane Science. 2008;322(1):196-203. DOI: 10.1016/j.memsci.2008.05.029

11. Kang W, Guo L, Fan H, Meng L, Li Y. Flocculation, coalescence and migration of dispersed phase droplets and oil-water separation in heavy oil emulsion. Journal of Petroleum Science and Engineering. 2012;81:177-181. DOI: 10.1016/j. petrol.2011.12.011

12. Böddeker KW. Liquid Separations with Membranes: An Introduction to Barrier Interference. Berlin: Springer; 2008.

13. Su TJ, Lu JR, Cui ZF, Thomas RK. Fouling of ceramic membranes by albumins under dynamic filtration conditions. Journal of Membrane Science. 2000;173(2):167-178. DOI: 10.1016/S0376-7388(00)00370-7

14. Boributh S, Chanachai A, Jiraratananon R. Modification of PVDF membrane by chitosan solution for reducing protein fouling. Journal of Membrane Science. 2009;342(1-2):97-104. DOI: $10.1016 /$ j.memsci.2009.06.022

15. Colle RD, Longo E, Fontes SR. Demulsification of water/sunflower oil emulsions by a tangential filtration process using chemically impregnated ceramic tubes. Journal of Membrane Science. 2007;289(1-2):58-66. DOI: 10.1016/j.memsci.2006.11.048

16. Fontes SR, Queiroz VMS, Longo E, Antunes MV. Tubular microporous alumina structure for demulsifying vegetable oil/ water emulsions and concentrating macromolecular suspensions.
Separation and Purification Technology. 2005;44(3):235-241. DOI: 10.1016/j.seppur.2005.02.001

17. Mohammadi T, Pak A, Karbassian M, Golshan M. Effect of operating conditions on microfiltration of an oil-water emulsion by a kaolin membrane. Desalination. 2004;168:201-205. DOI: 10.1016/j.desal.2004.06.188

18. Fang J, Qin G, Wei W, Zhao X, Jiang L. Elaboration of new ceramic membrane from spherical fly ash for microfiltration of rigid particle suspension and oil-in-water emulsion. Desalination. 2013;311:113-126. DOI: 10.1016/j.desal.2012.11.008

19. Scott K. Handbook of Industrial Membranes. $1^{\text {st }}$ ed. Oxford: Elsevier Advanced Technology; 1995.

20. Biron DS, Poleto P, Duarte J, Zeni M, Bergmann CP, Santos V. Preparation and Characterization of PA66/Alumina Composite Membrane. Materials Research. 2015;18(4):748-755. DOI: 10.1590/1516-1439.004715

21. Mulder M. Basic Principles of Membrane Technology. $2^{\text {nd }} e d$. Dordrecht: Kluwer Academic Publishers; 1996.

22. Sun D, Duan X, Li W, Zho D. Demulsification of water-inoil emulsion by using porous glass membrane. Journal of Membrane Science. 1998;146(1):65-72. DOI: 10.1016/S03767388(98)00096-9

23. Machado RMD, Haneda RN, Trevisan BP, Fontes SR. Effect of enzymatic treatment on the cross-flow microfiltration of açaí pulp: Analysis of the fouling and recovery of phytochemicals. Journal of Food Engineering. 2012;113(3):442-452. DOI: 10.1016/j.jfoodeng.2012.06.022

24. Wei W, Xia S, Liu G, Gu X, Jin W, Xu N. Interfacial adhesion between polymer separation layer and ceramic support for composite membrane. Materials, Interfaces and Eletrochemical Phenomena. 2010;56(6):1584-1592. DOI: 10.1002/aic.12086

25. Cheryan M. Ultrafiltration and Microfiltration Handbook. $2^{\text {nd }}$ ed. Boca Raton: CRC Press; 1998. 552 p.

26. Zeman LJ, Zydney AL. Microfiltration and Ultrafiltration: Principles and applications. New York: Marcel Dekker; 1996.

27. Nieuwenhuijzen AV, Van der Graaf J, eds. Handbook on Particle Separation Processes. London: IWA Publishing; 2011. 288 p. 